\title{
Conization of the Cervix Using Harmonic Scalpe1
}

\author{
Ryo Konno, Jun-ichi Akahira, Tsukasa Igarashi, \\ Hiromitsu Yamakawa, Shinji Sato and Akira Yajima \\ Department of Obstetrics and Gynecology, Tohoku \\ University School of Medicine, Sendai 980-8574
}

Konno, R., Akahira, J., Igarashi, T., Yamakawa, H., Sato, S. and Yajima, A. Conization of the Cervix Using Harmonic Scalpel. Tohoku J. Exp. Med., 1999, 189 (3), 171-178 — Conization, as a surgical treatment for cervical intraepithelial neoplasm (CIN), is a good method that preserves reproductive functions. Technological developments have introduced a wide variety of energy sources for surgical procedures. Traditional cold knife conization has been replaced by laser conization and by the loop electrosurgical excisional procedure (LEEP). However, laser conization and LEEP have some disadvantages. Laser conization requires expensive equipment. LEEP induces electrocautery artifacts and cannot excise the cervical tissue as a single-piece, because of the various extensions and depths of lesion, so that evaluation of the margins is sometimes not possible. Laser conization and LEEP both generate smoke. The presence of smoke is not only inconvenient, but also dangerous. Harmonic Scalpel (HS), ultrasonic cutting and coagulation system, is a new surgical tool that cuts and coagulates using ultrasonic mechanical vibrations. Eleven women with CIN III underwent conization using HS. HS eliminated the major disadvantages of electrosurgery and laser surgery. No complications during conization were observed. Postoperative hemorrhage was noted in only one patient. Histological diagnosis was not affected by heat or ultrasound. This surgical method using HS is characterized by negligible bleeding, a good visual field not obscured by smoke and resection of an ideal shape that fits the size of the lesion. It is concluded that this method overcomes most problems associated with conization using conventional methods. —_ conization; cervical intraepithelial neoplasia; Harmonic Scalpel; surgical procedure (C) 1999 Tohoku University Medical Press

Technological developments in surgical practice have introduced a wide variety of energy sources for tissue dissection. Traditional conization using a cold knife is a good method for patients who require subsequent fertility, although the complication rate is high after this minor surgical procedure. The most serious complication is hemorrhage both during and after this procedure.

Recently, the traditional surgical technique of cold knife conization has been

Received March 29, 1999; revision accepted for publication October 19, 1999.

Address for reprints: Ryo Konno, M.D., Department of Obstetrics and Gynecology,

Tohoku University School of Medicine, 1-1 Seiryomachi, Aoba-ku, Sendai 980-8574, Japan. e-mail: konno@ob-gy.med.tohoku.ac.jp

Harmonic Scalpel is a registrated trademark of Ethicon Endo-Surgery, Incorporated. 
replaced by laser conization and by the loop electrosurgical excisional procedure (LEEP) (Larsson et al. 1983). However, laser conization requires very expensive equipment, is time consuming and alters the tissue significantly. The LEEP appears to be technically easier and less time consuming, but sometimes induces electrocautery artifact so that evaluation of the margins is not possible (Mathevet et al. 1994). These artifacts lead to difficulties in the histological evaluation of the margins.

Another problem is smoke. Lasers as well as electrosurgical units generate considerable amount of smoke during use, making them less than optimal. The presence of smoke is not only inconvenient and time consuming, as evacuation of the smoke is necessary to provide good visualization, but it is also dangerous (Corbitt 1991; Voyles et al. 1991).

The ideal energy form used in surgery should be safe for both the patient and operating room personnel. A major disadvantage of electrosurgery is that the patient is in the electrical circuit and can suffer significant burns if she is not correctly grounded (Voyles et al. 1991).

Harmonic Scalpel (HS) (Johnson \& Johnson Medical Japan, Tokyo) is a new surgical tool that cuts and coagulates by converting electrical energy into ultrasonic mechanical vibrations. The ultrasonically activated scalpel is composed of a generator, handpiece and blade. The handpiece houses the acoustic transducer. The acoustic transducer consists of a stack of piezoelectric ceramic sandwiched under pressure between two metal cylinders. The three components of the acoustic system vibrate harmonically at $55000 \mathrm{~Hz}$ (Amaral 1994).

This study describes the development of a surgical procedure of conization using HS without electric or laser energy.

\section{Materials and Methods}

\section{Patients}

Between November 1997 and October 1998, 11 women with cervical intraepithelial neoplasia (CIN) III, including seven carcinoma in situ and four severe dysplasia, underwent conization using $\mathrm{HS}$ in Tohoku University Hospital. Preoperative cytology and histology of punch biopsies are summarized in Table 1. Integrated preoperative diagnosis was performed by means of cytology, and colposcopically-directed punch biopsy. No patient included in this study was pregnant at the time of conization. All patients gave their informed consent to participate in this study.

\section{Surgical procedure}

The conization was performed in admission with the patient under spinal anesthesia. To reduce bleeding, the bilateral descending branches of the uterine arteries were ligated with Vicryl 1-0 (Johnson \& Johnson Medical Japan) at 3 and 9 o'clock positions. The portio and vaginal mucosal surface were stained with 
TABLE 1. Patients and background factors

\begin{tabular}{|c|c|c|c|c|c|c|}
\hline $\begin{array}{l}\text { Case } \\
\text { No. }\end{array}$ & $\begin{array}{l}\text { Age } \\
\text { (Years) }\end{array}$ & Gravida & Para & $\begin{array}{l}\text { Preoperative } \\
\text { cytology }\end{array}$ & $\begin{array}{l}\text { Histology of } \\
\text { punch biopsies }\end{array}$ & $\begin{array}{l}\text { Preoperative } \\
\text { diagnosis }\end{array}$ \\
\hline 1 & 35 & 3 & 2 & $\begin{array}{l}\text { HGSIL/CIN III } \\
\text { /severe dysplasia }\end{array}$ & $\begin{array}{l}\text { CIN III } \\
\text { /severe dysplasia }\end{array}$ & $\begin{array}{l}\text { CIN III } \\
\text { /severe dysplasia }\end{array}$ \\
\hline 2 & 25 & 0 & 0 & $\begin{array}{l}\text { HGSIL/CIN III } \\
\text { / carcinoma in situ }\end{array}$ & $\begin{array}{l}\text { CIN III } \\
\text { / carcinoma in situ }\end{array}$ & $\begin{array}{l}\text { CIN III } \\
\text { / carcinoma in situ }\end{array}$ \\
\hline 3 & 27 & 1 & 1 & $\begin{array}{l}\text { HGSIL/CIN III } \\
\text { / carcinoma in situ }\end{array}$ & $\begin{array}{l}\text { CIN III } \\
\text { / carcinoma in situ }\end{array}$ & $\begin{array}{l}\text { CIN III } \\
\text { / carcinoma in situ }\end{array}$ \\
\hline 4 & 30 & 0 & 0 & $\begin{array}{l}\text { HGSIL/CIN III } \\
\text { / carcinoma in situ }\end{array}$ & $\begin{array}{l}\text { CIN III } \\
\text { / carcinoma in situ }\end{array}$ & $\begin{array}{l}\text { CIN III } \\
\text { /carcinoma in situ }\end{array}$ \\
\hline 5 & 30 & 4 & 2 & $\begin{array}{l}\text { HGSIL/CIN III } \\
\text { / carcinoma in situ }\end{array}$ & $\begin{array}{l}\text { CIN II } \\
\text { /moderate dysplasia }\end{array}$ & $\begin{array}{l}\text { CIN III } \\
\text { / carcinoma in situ }\end{array}$ \\
\hline 6 & 50 & 2 & 2 & $\begin{array}{l}\text { HGSIL/CIN II } \\
\text { /moderate dysplasia }\end{array}$ & $\begin{array}{l}\text { CIN III } \\
\text { / carcinoma in situ }\end{array}$ & $\begin{array}{l}\text { CIN III } \\
/ \text { carcinoma in situ }\end{array}$ \\
\hline 7 & 33 & 0 & 0 & $\begin{array}{l}\text { HGSIL/CIN III } \\
\text { / carcinoma in situ }\end{array}$ & $\begin{array}{l}\text { CIN III } \\
\text { / carcinoma in situ }\end{array}$ & $\begin{array}{l}\text { CIN III } \\
\text { / carcinoma in situ }\end{array}$ \\
\hline 8 & 36 & 0 & 0 & $\begin{array}{l}\text { HGSIL/CIN III } \\
\text { /severe dysplasia }\end{array}$ & $\begin{array}{l}\text { CIN I } \\
/ \text { mild dysplasia }\end{array}$ & $\begin{array}{l}\text { CIN III } \\
\text { /severe dysplasia }\end{array}$ \\
\hline 9 & 36 & 0 & 0 & $\begin{array}{l}\text { HGSIL/CIN III } \\
\text { / carcinoma in situ }\end{array}$ & $\begin{array}{l}\text { CIN III } \\
\text { /carcinoma in situ }\end{array}$ & $\begin{array}{l}\text { CIN III } \\
\text { /carcinoma in situ }\end{array}$ \\
\hline 10 & 35 & 2 & 2 & $\begin{array}{l}\text { HGSIL/CIN III } \\
\text { / carcinoma in situ }\end{array}$ & $\begin{array}{l}\text { CIN III } \\
\text { / carcinoma in situ }\end{array}$ & $\begin{array}{l}\text { CIN III } \\
\text { / carcinoma in situ }\end{array}$ \\
\hline 11 & 19 & 2 & 2 & $\begin{array}{l}\text { LGSIL/CIN I } \\
\text { /mild dysplasia }\end{array}$ & $\begin{array}{l}\text { CIN III } \\
\text { /severe dysplasia }\end{array}$ & $\begin{array}{l}\text { CIN III } \\
\text { /severe dysplasia }\end{array}$ \\
\hline
\end{tabular}

HGSIL, high-grade squamous intraepithelilal lesion; LGSIL, low-grade squamous intraepithelilal lesion; CIN, cervical intraepithelial neoplasia.

$1 \%$ iodine solution to delineate the transformation zone and the lesion (Schiller's test). The size of the cone was determined by the extent of the lesion. The cervix was infiltrated with vasopressin (Pitressin, 20 vasopressin units, Sankyo, Tokyo) - 1:50-saline 30-ml solution or lidocaine hydrochloride-1: 100000 epinephrine (Xylocaine with epinephrine, Fujisawa, Osaka) 30-ml, and rendered ischemic. The anterior and posterior cervical lips were tied with Vicryl 1-0 at the external areas of the lesion as recognized by Schiller's test. The tied Vicryl was used for traction to set a good position for the excision of the cone. The conical portion of the cervical tissue was resected by means of the HS2 hook blade of the HS on level 3 power setting. After marking the 12,3,6 and 9 o'clock positions, careful circumcision of the mucosal surface of the portio was carried out for the precise removal of the cone. The blade was inserted into the iodine-positive area of the cervix at the 9 o'clock position, and moved in a clockwise direction around the portio (Fig. 1). The blade of the HS pointed to the cervical canal. The cone was excised from the portio (Figs. 2 and 3), including the entire cervical canal. To avoid the constriction of the cervical canal, a Nelaton catheter was inserted into the cervical canal. After hematostasis had been achieved, the wound surface 


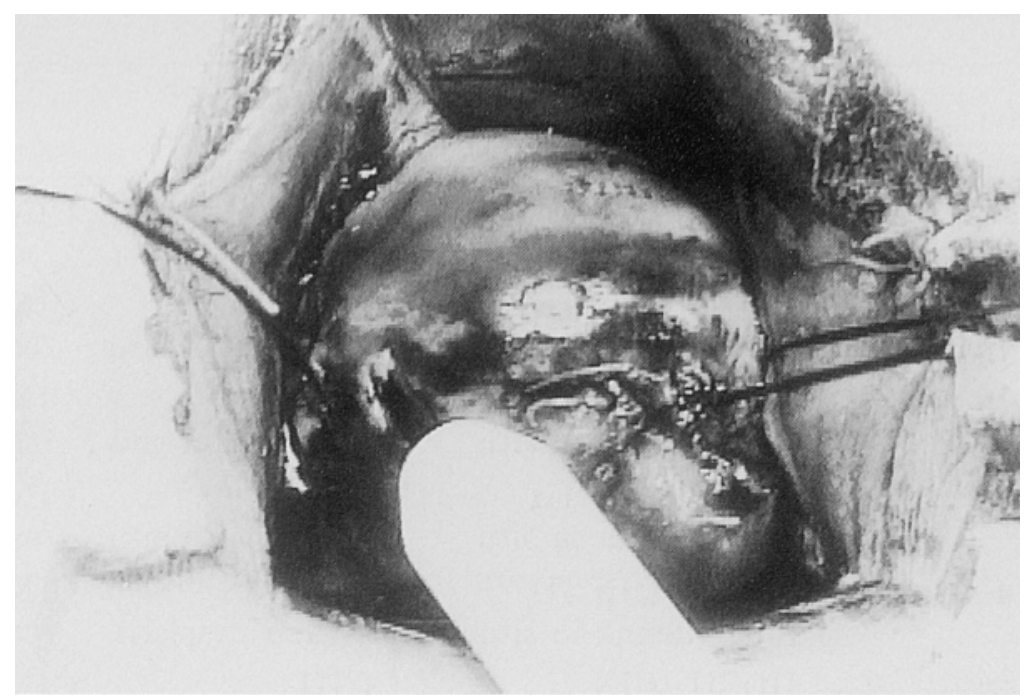

Fig. 1. Procedure of conization using Harmonic Scalpel (1). Circumcision of the mucosal surface was carried in a clockwise direction around the portio. The blade of Harmonic Scalpel was inserted into the iodine-positive area of the cervix at the 9 o'clock position.

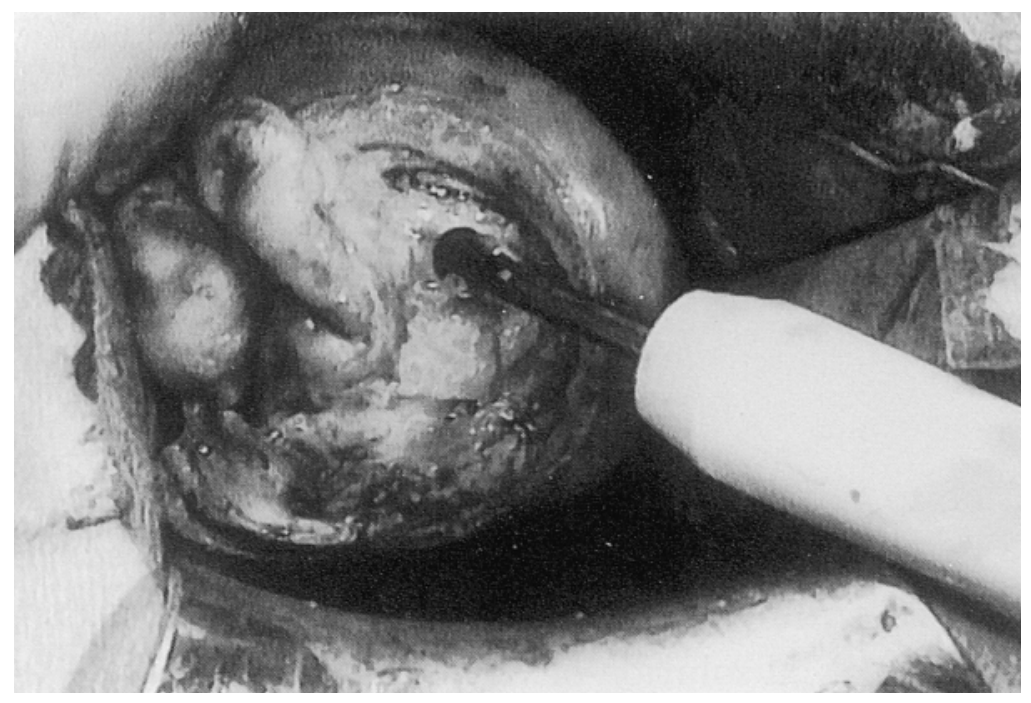

Fig. 2. Procedure of conization using Harmonic Scalpel (2). The blade of the Harmonic Scalpel pointed to the cervical canal. The cone was excised from the portio.

was tamponaded with gauze.

\section{Evaluation}

Intraoperative blood loss and the operative time were measured and recorded. The operative time was defined as from ligation of the branches of the uterine vessels until tamponading with the gauze. Postoperative hemorrhage, constriction of the cervical canal and other complications were reviewed in the outpatient clinic records.

After being fixed in buffered formalin and embedded in paraffin, the cone 


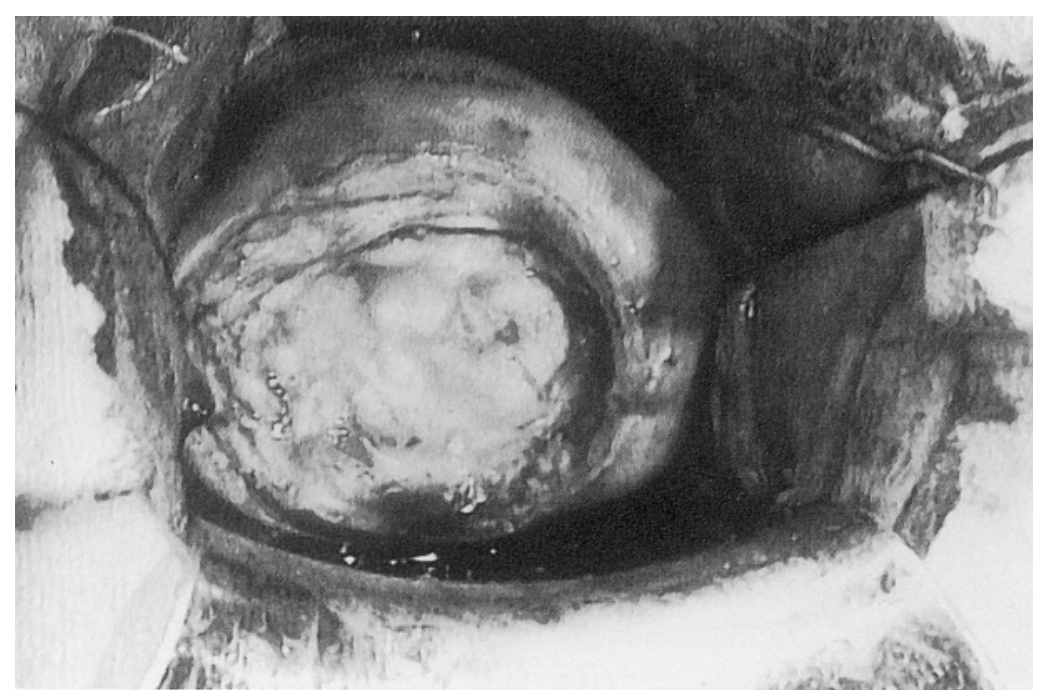

Fig. 3. Conization using HS was performed with little amount of intraoperative bleeding. It was unnecessary for the wound surface and incision margins to be treated with other instruments or suturing for bleeding.

samples were stained with hematoxylin and eosin (H \& E), diagnosed histologically and reviewed with special attention to thermal artifacts.

The present study was not concerned with the evaluation of the conization technique as a day-surgery for outpatients, but was intended to develop the surgical method and to confirm safeness.

\section{RESULTS}

Background findings of the patients and factors related to the operation are given in Tables 1 and 2. The mean age of patients was 34.5 years old (range 1950 years old). The mean postoperative hospital stay was 3.2 days (range 2-5 days). Conization using HS was performed with only a minor amount of intraoperative bleeding. Blood loss during the procedure was less than $10 \mathrm{ml}$ in 10 of 11 cases. It was unnecessary for the wound surface and incision margins to be treated with other instruments or suturing for bleeding. Gross evaluation following conical excision using HS demonstrated no charred or desiccated surfaces (Fig. 3).

The mean operative time, including the preparation before excision, such as ligation of uterine vessel branches or Schiller's test, was 21.4 minutes (range 13-40 minutes). No complications involving the procedure were noted. HS eliminated the major disadvantages of electrosurgery and laser therapy. Since HS cut and coagulated tissue without generating smoke, the visual field was not obscured during the conization.

Postoperative hemorrhage was noted in one patient. She was treated with bipolar electrocoagulation in the outpatient clinic. No cervical stenosis was observed in any patients. Other postoperative complications, including sterility or incompetent cervix, have not been recognized during the observation period 
TABLE 2. Patients and factors related to the opeartion

\begin{tabular}{|c|c|c|c|c|c|}
\hline $\begin{array}{l}\text { Case } \\
\text { No. }\end{array}$ & $\begin{array}{l}\text { Operative time } \\
\text { (Minutes) }\end{array}$ & $\begin{array}{l}\text { Intraoperative } \\
\text { bleeding }\end{array}$ & $\begin{array}{l}\text { Histology of } \\
\text { cone specimens }\end{array}$ & $\begin{array}{l}\text { Surgical } \\
\text { margin }\end{array}$ & Complication \\
\hline 1 & 25 & $<10 \mathrm{ml}$ & $\begin{array}{l}\text { CIN III } \\
\text { /severe dysplasia }\end{array}$ & Intact & None \\
\hline 2 & 15 & $<10 \mathrm{ml}$ & $\begin{array}{l}\text { CIN III } \\
\text { /carcinoma in situ }\end{array}$ & Intact & None \\
\hline 3 & 22 & $<10 \mathrm{ml}$ & $\begin{array}{l}\text { CIN II } \\
\text { /moderate dysplasia }\end{array}$ & Intact & None \\
\hline 4 & 35 & $<10 \mathrm{ml}$ & $\begin{array}{l}\text { CIN III } \\
\text { / carcinoma in situ }\end{array}$ & Intact & None \\
\hline 5 & 20 & $<10 \mathrm{ml}$ & $\begin{array}{l}\text { CIN III } \\
\text { / carcinoma in situ }\end{array}$ & Intact & $\begin{array}{l}\text { Postoperative } \\
\text { hemorrage }\end{array}$ \\
\hline 6 & 20 & $<10 \mathrm{ml}$ & $\begin{array}{l}\text { CIN II } \\
/ \text { moderate dysplasia }\end{array}$ & Intact & None \\
\hline 7 & 17 & $<10 \mathrm{ml}$ & $\begin{array}{l}\text { CIN III } \\
\text { / carcinoma in situ }\end{array}$ & Intact & None \\
\hline 8 & 14 & $<10 \mathrm{ml}$ & No residual lesion & Intact & None \\
\hline 9 & 15 & $<10 \mathrm{ml}$ & $\begin{array}{l}\text { CIN III } \\
\text { / carcinoma in situ }\end{array}$ & Intact & None \\
\hline 10 & 40 & $52 \mathrm{ml}$ & $\begin{array}{l}\text { CIN III } \\
\text { / carcinoma in situ }\end{array}$ & Intact & None \\
\hline 11 & 13 & $<10 \mathrm{ml}$ & $\begin{array}{l}\text { CIN II } \\
\text { /moderate dysplasia }\end{array}$ & Intact & None \\
\hline
\end{tabular}

CIN, Cervical intraepithelial neoplasia.

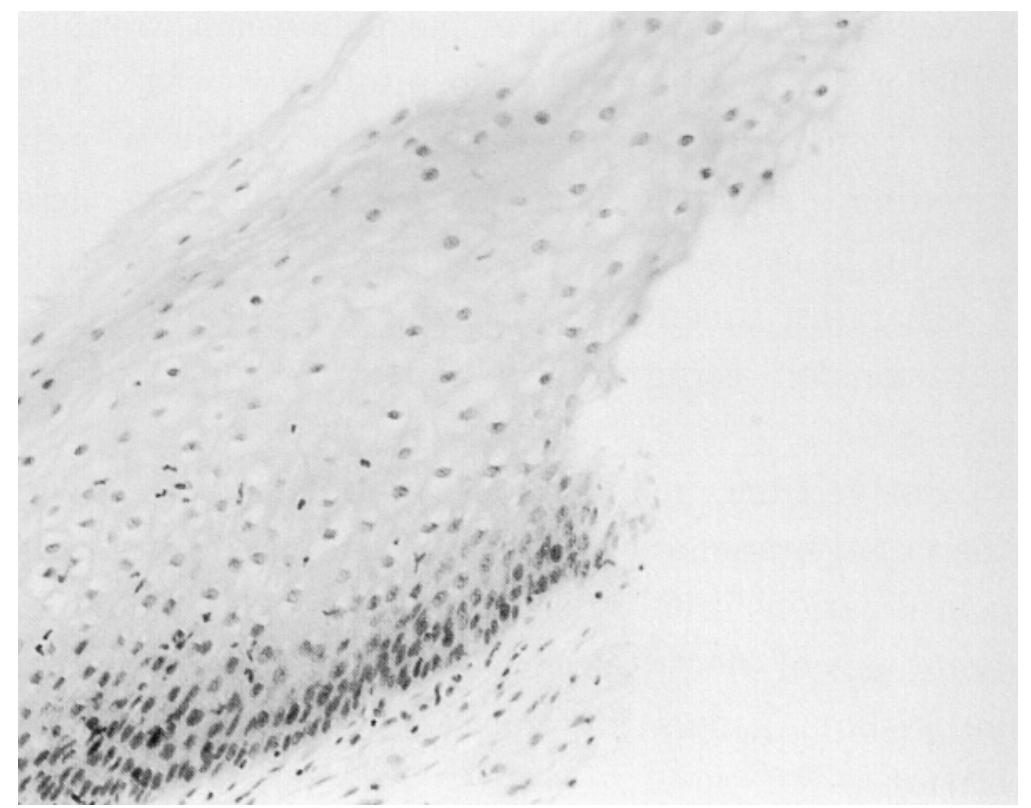

Fig. 4. Histological specimen of the cut margin after conization using HS $(\mathrm{H} \& \mathrm{E}, \times 200)$. No tissue degeneration is observed in the cut margin and histological diagnosis is not affected by heat or ultrasound. 
(mean 9.7 months). Histological diagnosis is shown in Table 2. Surgical margins of all cone specimens were intact. No patients were additionally treated for residual lesions.

Fig. 4 shows an $\mathrm{H} \& \mathrm{E}$ histological specimen of the cut margin after conization using HS. No tissue degeneration was observed in the cut margin and histological diagnosis was not affected by heat or ultrasound.

\section{Discussion}

The cutting mechanism for HS is different from that observed with electrosurgery or laser surgery. The most important mechanism of HS is the actual "power cutting" offered by a blade vibrating 55000 times per second over a distance of 80 microns. This is best-observed in high protein-density areas, such as collagen- or muscle rich tissues and also the cervix. In contrast, cutting with electorosurgery or laser occurs when the temperature of cells increases to such a point that concomitant increase in gas pressure explodes the cells (Pearce 1980).

The ultrasonically activated scalpel denatures protein by the transfer of mechanical energy to the tissue that is sufficient to break hydrogen bonds and by the generation of heat from friction that results from the coupling of the blade with the tissue. Thermographic analysis has demonstrated that ultrasonically activated coagulation does not heat tissue above $80^{\circ} \mathrm{C}$. As a result, tissue does not desiccate from a loss of moisture, and does not burn (Amaral 1994).

In addition, it has been shown in animal studies that HS does not cause significant thermal damage. Skin incision made with the ultrasonically activated scalpel and cold knife heal almost identically and are significantly superior to electrosurgery (Hambley 1988).

It is important for the surgeon that the ultrasonically activated scalpel provides tissue and tension discrimination and tactile feedback similar to that of a conventional scalpel. The only significant differences between HS and a cold, conventional, steel knife are that HS provides facilitated simultaneous cutting and coagulation (Amaral 1994).

HS has been widely applied in both laparoscopic and open surgery. In the gynecological field, it has been used in laparoscopic myomectomy (Konno and Nagase 1994; Stringer 1994) and hysterectomy (Robbins and Ferland 1995). The advantages and characteristics of HS appear to make it suitable for conization as well as laparoscopic surgery. HS provides effective coagulation and cutting for conization.

In electrosurgery, there are various sizes of loop electrodes. However, removal as a single-piece is difficult due to the extension and depth of the lesion. At the time of histological diagnosis tissue reconstruction is sometimes difficult, and there is a risk of incomplete resection on the cervical canal side.

This surgical method is characterized by only negligible bleeding due to the use of HS, a visual field not obscured by smoke and resection of a cone with a free 
shape that fits the size and site of the lesion. Therefore, there is no difficulty in reconstruction of specimens at the time of histological diagnosis. In addition, since coagulation occurs at a low temperature compared with the electrosurgery or laser therapy, thermal injury at the surgical margin is negligible. Therefore, the presence or absence of the lesion at the cut margin can be accurately determined, which is most important in histological diagnosis after conization of cervical lesions.

In the present study, the surgery was performed on inpatients to confirm the safeness of procedure and to observe the post-operative course. Since there were no severe complications observed and the technique was safe and easy, it appears that this method can be applied to outpatients.

However, HS has the following disadvantages. 1) The blade is straight and thick, and its tip is difficult to observe in deep areas. 2) Mist is generated. At present, improvement in the shape of the tip of the blade and development of a curved blade are underway. It is important to emphasize that, despite these disadvantages, this surgical method overcomes most problems associated with conventional conization. Further studies are necessary on the complication rate and the presence or absence of residual lesions in additional cases treated using this method over a longer follow-up period.

\section{References}

1) Amaral, J.F. (1994) The experimental development of an ultrasonically activated scalpel for laparoscopic use. Surg. Laparosc. Endosc., 4, 92-99.

2) Corbitt, J. (1991) Laparoscopic cholecystectomy: Laser versus electro surgery. Surg. Laparosc. Endosc., 1, 85-88.

3) Hambley, R., Hebda, P.A., Abell, E., Cohen, B. \& Jegasothy, B.V. (1988) Wound healing of skin incisions produced by ultrasonically vibrating knife, scalpel, electrosurgery, and carbon oxide laser. J. Dermatol. Surg. Oncol., 14, 11.

4) Konno, R. \& Nagase, S. (1994) Usefulness of Harmonic Scalpel (Ultrasonic cutting and coagulation system) in laparoscopic surgery. Clin. Gynecol. Obstet., 48, 809-812. (in Japanese)

5) Larsson, G., Gullberg, B. \& Grundsell, H. (1983) A comparison of complication of laser and cold knife conization. Obstet. Gynecol., 62, 213-217.

6) Mathevet, P., Dargent, D., Roy, M. \& Beau, G. (1994) A randomized prospective study comparing three techniques of conization: Cold knife, laser, and LEEP. Gyenecol. Oncol., 54, 175-179.

7) Pearce, J.A. (1980) Cutting and coagulating processes. In: Electrosurgery, edited by J.A. Pearce, John Wiley and Sons, New York, 62-128.

8) Robbins, M.L. \& Ferland, R.J. (1995) Laoaroscopic assisted vaginal hysterectomy using the laparoscopic coagulating shears. J. Am. Gynecol. Laparosc., 2, 339-343.

9) Stringer, N.H. (1994) Laparoscopic myomectomy with the Harmonic Scalpel; A review of 25 cases. J. Gynecol. Surg., 10, 241-245.

10) Voyles, C.R., Petro, A.B., Meena, A.L., Haick, A.J. \& Koury, A.M. (1991) A practical approach to laparoscopic cholecystectomy. Am. J. Surg., 161, 365-369. 